\title{
Cerebral Oxygen Desaturation with Normal ICP and CPP in Severe TBI
}

\author{
Sylvain Palmer ${ }^{*}, 1$ and Mary Kay Bader ${ }^{2}$ \\ ${ }^{1}$ Orange County Neurological Associates, 26732 Crown Valley Parkway, Suite 561, Mission Viejo, CA 92651, USA \\ ${ }^{2}$ Mission Hospital and Regional Medical Center, 27000 Medical Center Road, Mission Viejo, CA 92691, USA
}

\begin{abstract}
Introduction: Standard monitoring of severe traumatic brain injury patients (TBI) by intracranial pressure (ICP) and cerebral perfusion pressure (CPP) monitoring fails to recognize episodes of cerebral oxygen desaturation. We found and characterized frequent episodes of desaturation of jugular venous oxygen $(\mathrm{SjO} 2)$ in the face of normal ICP and CPP.

Methods: Fifty six patients with severe TBI had $\mathrm{SjO} 2$ and ICP monitors placed. The charts were retrospectively reviewed and all episodes of desaturation were recorded and characterized.

Results: Nineteen patients had episodes of desaturation with normal ICP and CPP. The average GCS score was 5.8. 63\% of desaturations occurred in the first 24 hours, $17 \%$ of desaturations occurred in 24-48 hours, and 20\% occurred in 48-72 hours. The depth of desaturation was $50-54 \%$ in $50 \%$ of instances, $45-49 \%$ in $37 \%$ of instances, and $40-44 \%$ in $13 \%$ of instances. The duration of the desaturation episodes was less than 10 minutes in $47 \%, 10-30$ minutes in $17 \%, 30-60$ minutes in $23 \%$, and greater than 50 minutes in $13 \%$. Treatment of the desaturation was elevation of FIO2 in all patients, elevation of pCO2 in 15 patients, volume expansion in 9 patients, pressors in 9 patients, and Propofol in 5 patients.

Conclusions: The monitoring of severe TBI patients with ICP and CPP alone is insufficient to recognize cerebral oxygen desaturation episodes in $34 \%$ of patients. The monitoring of $\mathrm{SjO} 2$ facilitates the recognition and treatment of these episodes.
\end{abstract}

Keywords: Traumatic brain injury, intracranial pressure monitoring, cerebral perfusion monitoring, jugular venous oxygen saturation, cerebral ischemia, cerebral oxygen monitoring.

\section{INTRODUCTION}

The treatment of traumatic brain injury (TBI) has advanced considerably over the last decade. The publication of "The Guidelines for the Treatment of Severe Head Injury", published by the AANS/BTF in 1995 and last revised in 2007 established the scientific basis for modern TBI care [1]. In the Guidelines it was noted that hyperventilation should not be used without monitoring brain oxygenation because of the risk of cerebral hypoxia. The regular use of jugular bulb catheters in our patients to monitor the jugular oxygen saturation $(\mathrm{SjO} 2)$ led to a better understanding of the occurrence and incidence of cerebral desaturation. In particular, desaturation episodes were seen independent of elevations in intracranial pressure (ICP) with normal cerebral perfusion pressure (CPP). We reviewed all of our monitored patients to further characterize this phenomenon.

\section{MATERIALS AND METHODS}

All patients were cared for at Mission Hospital and Regional Medical Center, an ACS Level II trauma center. Inclusion criteria were: Glasgow Coma Scores (GCS) of 3-8, non-penetrating head injuries, and placement of ICP and $\mathrm{SjO} 2$ monitors. There were a total of 56 patients with severe TBI who received ICP and $\mathrm{SjO} 2$ monitors. A retrospective review of the prospectively collected data was undertaken for the first three days of hospitalization. This revealed that 19 patients had episodes of desaturation with normal ICP

*Address correspondence to this author at the 26732 Crown Valley Parkway, Suite 561, Mission Viejo, CA 92651, USA; Tel: 949-364-1060;

Fax: 949-364-5761; E-mail: sylvainpalmer@cox.net and CPP. There were 18 males and one female. The age ranged from 15-74 years with an average age of 40. The Glasgow Coma Score (GCS) ranged from 3 to 14 with two patients, with GCS of 10 and 14, deteriorating to lower levels in the first 24 hours. The average GCS was 5.8 with a median GCS of 6 . The injury severity score ranged from 16 to 50 with an average score of 30 and a median score of 26 .

All patients were admitted on the trauma service. The patients went to surgery within 24 hours of admission for placement of ventriculostomies, sometimes in conjunction with other decompressive procedures. The ventriculostomies were either Camino bolts (Integra NeuroSciences, Plainsville, NJ) or Codman ventricular catheters (Codman, Raynam, MA). Jugular bulb catheters (Abbott Laboratories, Chicago, IL) were placed by the trauma surgeons in the operating room or in the intensive care unit (ICU) utilizing fluoroscopic and ultrasound guidance. All patients were treated using a Severe TBI protocol based on the Guidelines integrated with $\mathrm{SjO} 2$ monitoring. Craniectomies were preformed when clinically indicated in 12 patients: 7 day one and 6 day 2-3 (one patient receiving an early and a late craniectomy). ICP and $\mathrm{SjO} 2$ were monitored for 3-22 days (average 11, median 10). Functionality of the $\mathrm{SjO} 2$ system was monitored continuously to assess catheter occlusion or malposition, and accuracy was confirmed atleast once every 12 hours by sending a venous sample to the laboratory. Ventilator days ranged from 3-58 days (average 22, median 20). ICU length of stay was 3-60 days (average 24, median 22). Hospital length of stay was 3-78 days (average 28, median 20 ). Hospital charges ranged from $\$ 66,104$ to $\$ 743,046$. Mechanism of injury was: motor vehicle accident $37 \%$, fall 
$37 \%$, bike vs auto $16 \%$, skateboard $5 \%$, pedestrian vs auto $5 \%$. Radiological findings were: cerebral edema 13, contusion 10, subdural hematoma 9, skull fracture 2, traumatic subarachnoid hemorrhage 1.

\section{RESULTS}

There were 56 patients who fit the initial selection criteria. Normal $\mathrm{SjO} 2$ levels $(55 \%-75 \%)$ were found in 30 patients $(54 \%)$. In this group 13 patients $(23 \%)$ had low ICP and $17(31 \%)$ had high ICP. Low SjO2 and high ICP $(>20)$ were found in 7 patients (13\%). Low $\mathrm{SjO} 2$ and low ICP and normal CPP were found in 19 patients (34\%). It is this group of 19 patients with low $\mathrm{SjO} 2$ in the face of normal ICP and CPP that we further characterized. One patient example is noted in Fig. (1).

The timing of the occurrences of desaturations was tabulated (Fig. 2). 63\% of desaturations occurred in the first 24 hours. $17 \%$ of desaturations occurred in $24-48$ hours and $20 \%$ occurred in $48-72$ hours. The severity of desaturations below 55\% was tabulated (Fig. 3). The depth of desaturation was $50-54 \%$ in $50 \%$ of instances, $45-49 \%$ in $37 \%$ of instances, and $40-44 \%$ in $13 \%$ of instances. The duration of desaturations was tabulated (Fig. 4). The duration of the desaturation episodes was less than 10 minutes in $47 \%, 10-30$ minutes in $17 \%, 30-60$ minutes in $23 \%$, and greater than 50 minutes in $13 \%$. The interventions most commonly utilized for treatment of the desaturation were elevation of FIO2 in all patients, elevation of $\mathrm{pCO} 2$ in 15 patients, volume expansion in 9 patients, pressors in 9 patients, and Propofol in 5 patients. GOS scores were: GOS 4\&5-68.4\%, GOS 2\&3$15.8 \%$, and GOS $1-15.8 \%$.
Craniectomies had been utilized for the control of ICP in 12 of the 19 patients (63\%). 7 patients had early craniectomies associated with the removal of an acute subdural hematoma. Six patients required a delayed crainiectomy for delayed elevations in ICP. One patient required both an early and a late crainiectomy.

\section{DISCUSSION}

Measures for decreasing the impact of TBI have been aimed at prevention of primary injury as well as prevention of secondary injury [1-4]. An extensive body of literature supports the importance of adequate monitoring and treatment to avoid secondary injury related to hypotension, hypoxia, and elevated ICP [2, 5-10]. Marion, et al., in 1991, showed that cerebral blood flow was reduced after TBI in the first $12-24$ hours [8]. Bouma, et al., in 1992, showed that there was a $31.4 \%$ incidence of ischemia in the first $3.1 \mathrm{~h}+/$ 2.1h after injury [11]. Chestnut, et al., in 1993, demonstrated that hypotension (BPsys $<90 \mathrm{mmHg}$ ) was associated with an increase in morbidity and mortality [3]. Robertson, et al., saw an increase in mortality in patients suffering episodes of cerebral oxygen desaturation [12].

In adopting the Guidelines into our clinical practice we established clinical protocols for the bedside management of the severe TBI patient. These have been previously published [13]. They incorporated The Guidelines and cerebral oxygen monitoring utilizing jugular bulb catheters to measure oxygen saturation ( $\mathrm{SjO} 2)$. The initial results of this work showed an improved outcome with decrease in mortality (GOS 1 ) from $43 \%$ to $27 \%$, a decrease in severe disability and vegetative state (GOS $2 \& 3$ ) from $30 \%$ to $11 \%$, and an

Example Patient

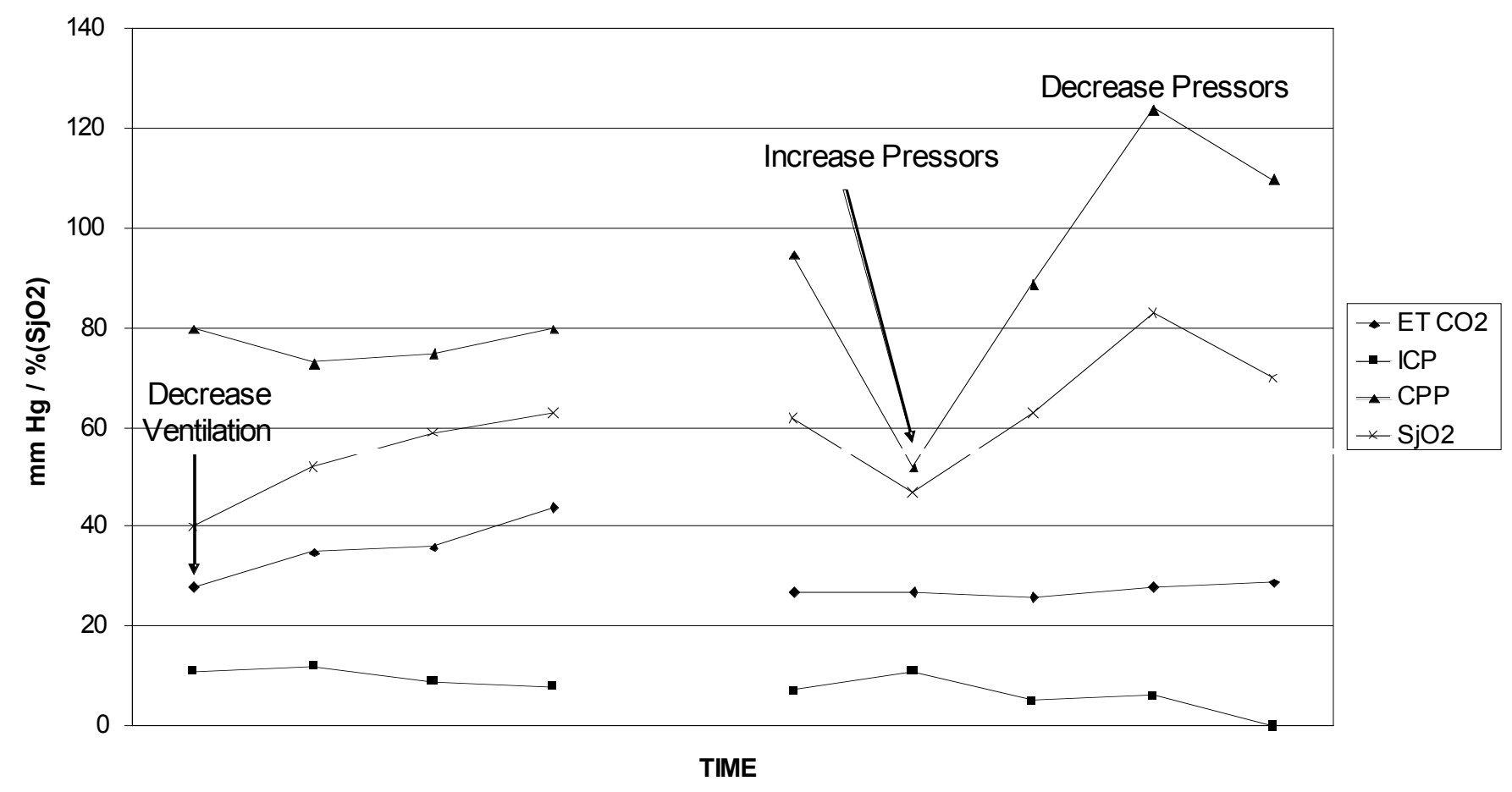

Fig. (1). 


\section{Timing of Desaturation}

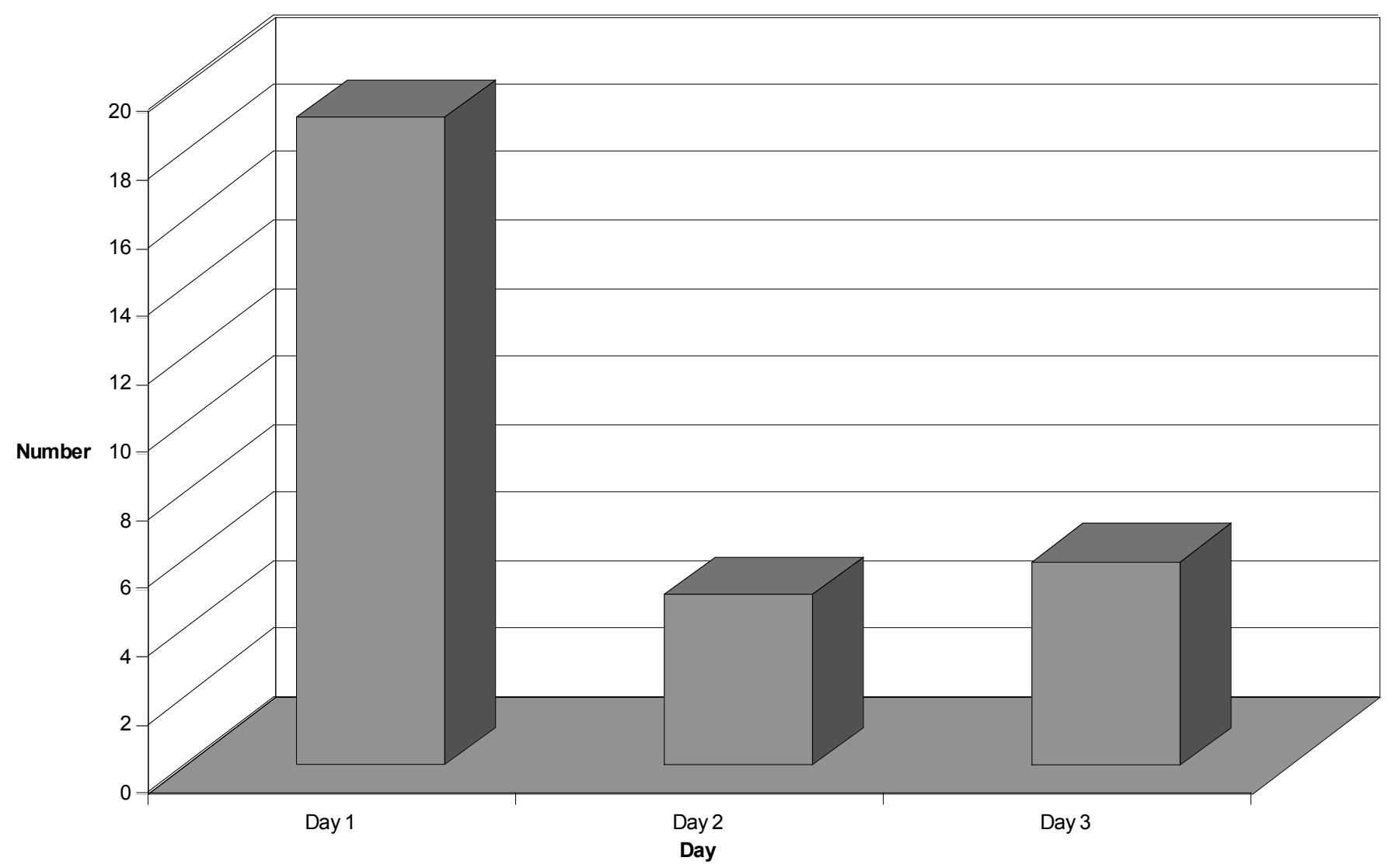

Fig. (2).

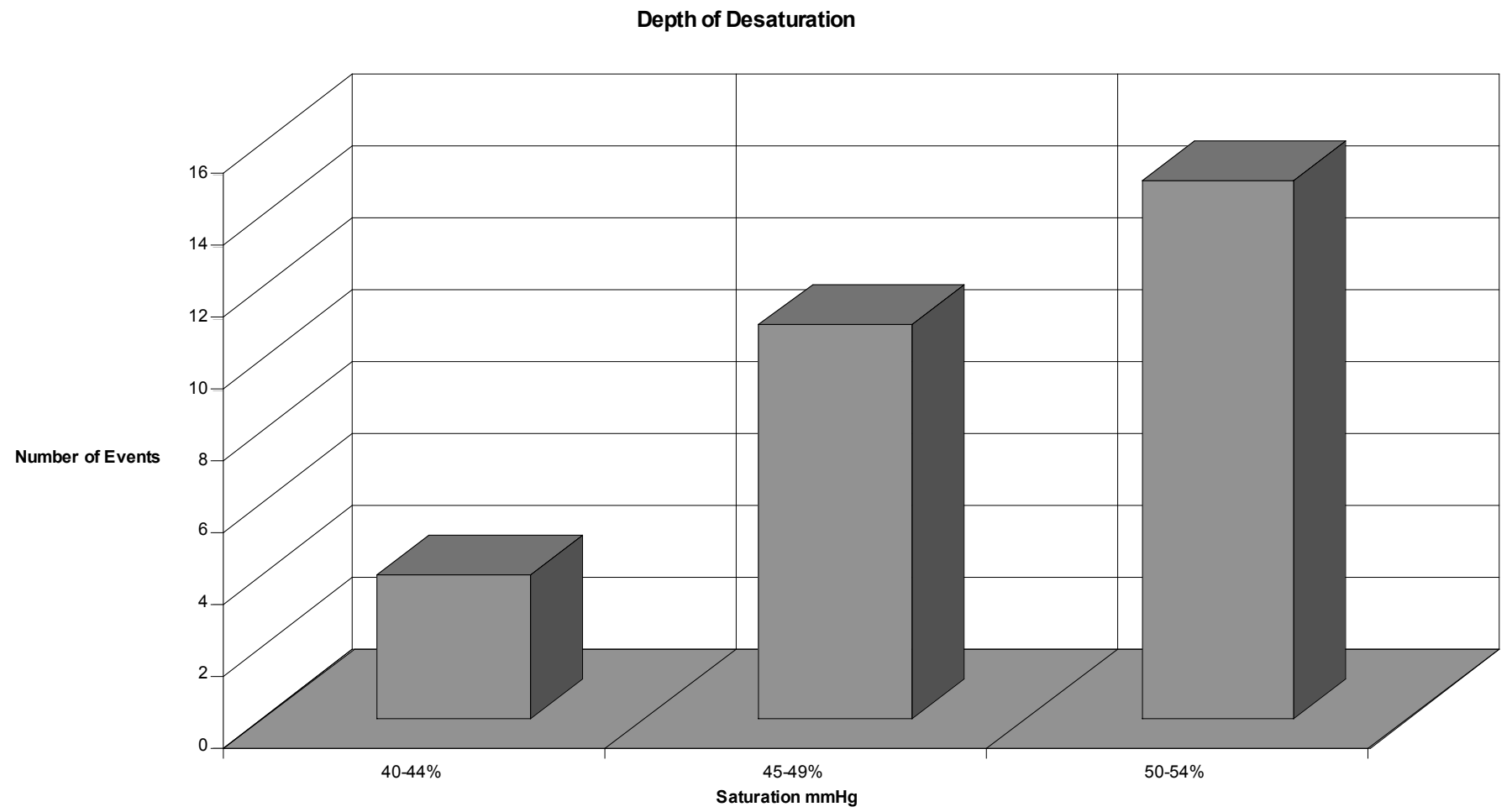

Fig. (3). 


\section{Length of Desaturation}

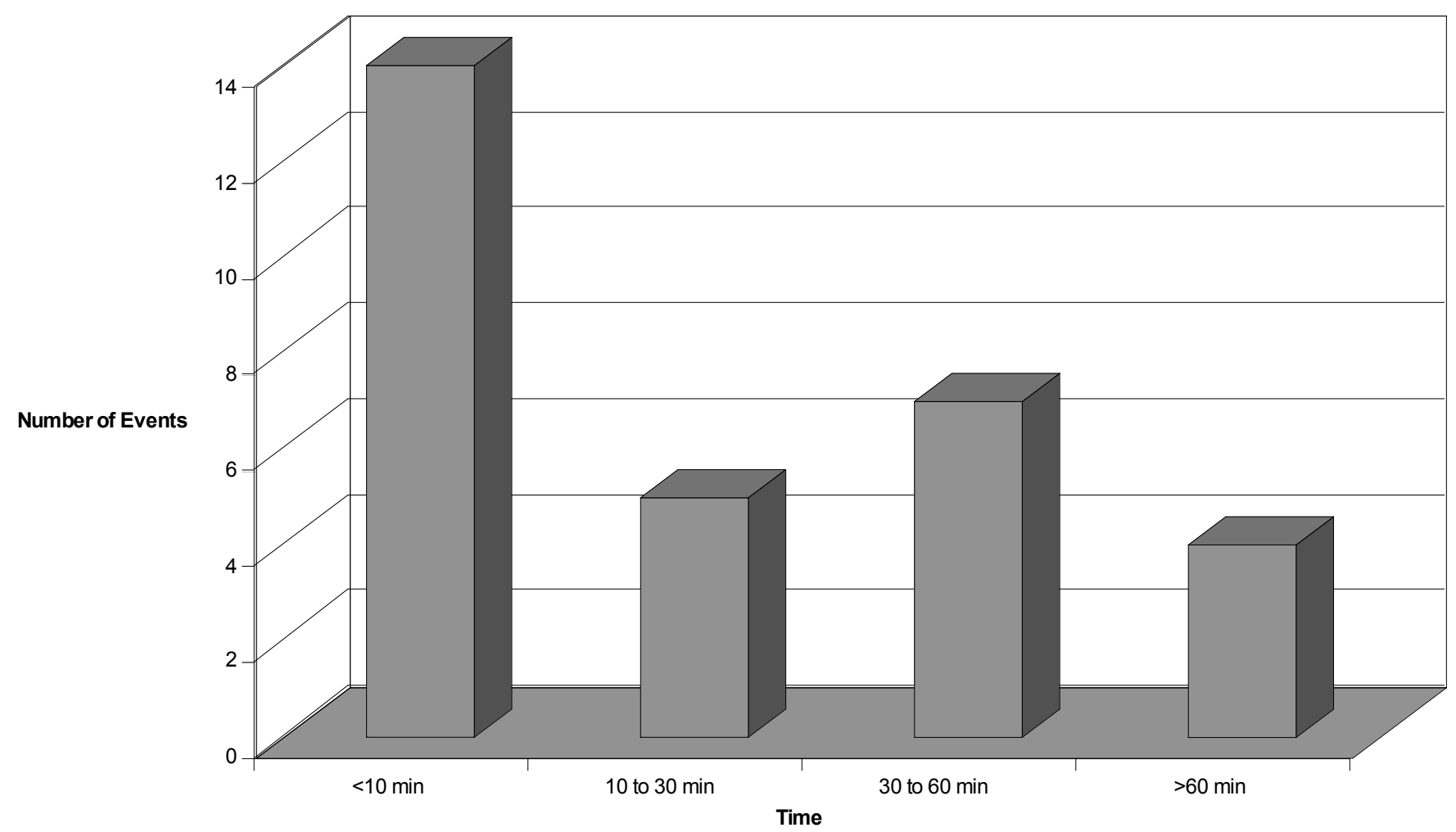

Fig. (4).

increase in good and moderate disability (GOS 4 \& 5) from $27 \%$ to $43 \%$ [13]. These numbers have been stable at last evaluation December 2006, $\mathrm{n}=193$, with GOS $1-13 \%$, GOS $2 \& 3-14.5 \%$, and GOS 4 \& 5-72.5\% (recent experience has included the use of intraparenchymal oxygen monitoring).

The adequacy of using ICP and CPP monitoring alone to direct clinical decision making has been brought into question in several studies. Graham, et al., in 1989, wrote that ischemic cell changes were found in $70 \%$ of brains following fatal severe TBI without clinical elevations in ICP [14]. van Santbrink, et al., in 1996, followed cerebral oxygenation in 22 severe TBI patients [15]. They looked at the correlation with multiple factors including ICP, $\mathrm{CPP}, \mathrm{SjO} 2, \mathrm{PbtO} 2$, among others. They found a weak correlation between cerebral oxygenation and either ICP or CPP. Using parenchymal oxygen monitoring, Harl, Artue, van den Brink, and Stochetti explored the causes of decreased cerebral oxygenation. Hartl, et al., in 1997, found that mannitol could control elevated ICP but had no effect on cerebral oxygenation in eleven patients [4]. They concluded that cerebral oxygenation should be followed separately from ICP. Artu, et al., in 1998, demonstrated that despite CPP in the therapeutic range that cerebral hypoxia was seen [16]. Increasing the CPP to supra-therapeutic levels could restore adequate oxygenation. This suggested that CPP monitoring alone was inadequate in avoiding cerebral hypoxia. Van den Brink, in 2000, demonstrated that early inadequate oxygen metabolism was seen in spite of aggressive treatment of ICP and CPP [17]. They found that cerebral oxygenation was an independent predictor of outcome. Stochetti et al. found in 9 patients with focal cerebral contusions that several had ab- normal $\mathrm{PbtO} 2$ in spite of the ICP and the CPP being in the normal range [18].

$\mathrm{SjO} 2$ monitoring has proven useful in better understanding the consequences of severe TBI. Shoon, et al., in 2002, looked at 116 severe TBI patients without elevated ICP on admission and found that the incidence of development of elevated ICP was significantly higher in patients with abnormal $\mathrm{SjO} 2$ [19]. The common causes were hyperventilation (40.7\%), hypovolemia $28.4 \%$, and anemia (21\%). They postulated that, "Early detection of disturbances in oxygen supply-demand relationship and prevention or resolution of the secondary insults which produce these disturbances, might lead to a reduction in the incidence of intracranial hypertension." In 2001, Cuza, et al., stated that, "Episodes of desaturation are frequent in neurocritical patients and are associated with increased mortality" [20].

Low cerebral oxygen is significantly correlated with poor outcome as shown by several authors utilizing parenchymal oxygen monitoring, including: van den Brink, Bardt, and Dings. van den Brink, in 2000, looked at 101 patients with severe TBI and found that hypoxia was an independent predictor of unfavorable outcome and death [17]. Barth et al., in 1998, reported that severe hypoxia for greater than 30 minutes resulted in substantially worse outcome than hypoxia limited to under 30 minutes [21]. Dings et al., in 1998, reported that patients with lower cerebral oxygenation showed lower Glasgow Outcome Scores (GOS) at 6 months [22]. Stiefel et al., showed significant improvement in patient outcomes when they added oxygen monitoring to their TBI treatment protocol [23]. 
In our study of 56 patients, 19 patients (34\%) had episodes of cerebral desaturation in spite of normal ICP. CPP was also above $60 \mathrm{mmHg}$ in all but one patient where it fell briefly to 50 (Fig. 1). The fact that ICP and CPP measurements failed to effectively predict cerebral oxygen desaturation left $34 \%$ of patients at risk for secondary hypoxic brain injury. This demonstrates the need for multimodality monitoring of severe TBI patients to include some form of cerebral oxygen monitoring. Latronico, et al., found that in 34 of 319 observations that $\mathrm{SjO} 2$ was abnormal in the face of normal ICP and CPP [24]. They did not modify treatment based on $\mathrm{SjO} 2$ abnormalities alone, but did treat if a low $\mathrm{SjO} 2$ was associated with hypovolemia or hypocapnia. Contrary to our conclusions, they concluded that intermittent $\mathrm{SjO} 2$ monitoring was not clinically useful.

An analysis of the timing, depth, and duration of desaturation episodes demonstrates several importation points of clinical relevance. The episodes occur early, are variable in depth, and are of short duration. Real time monitoring is of critical importance to allow the timely institution of treatments to correct the desaturations before secondary injury can occur. The use of critical thinking algorithms allows the caregiver at the bedside to institute appropriate corrective actions in real time without delays, which could result by the need to contact other medical care providers not at the bedside [25]. This empowerment of nursing and other bedside personnel accelerates the treatment of the patient while relieving the Neurosurgeon/Intensivist of frequent calls to handle issues adequately covered by protocol and competent bedside caregivers.

\section{CONCLUSION}

The monitoring of severe TBI patients with ICP and CPP alone is insufficient to recognize cerebral oxygen desaturation episodes in $34 \%$ of patients. The monitoring of $\mathrm{SjO} 2$ facilitates the recognition and treatment of these episodes. Critical thinking algorithms are invaluable in assisting in the real time management of these patients.

\section{REFERENCES}

[1] Bullock R, Chesnut RM, Clifton G, et al. Guidelines for the management of Severe Head Injury. Brain Trauma Foundation, New York, NY, 2000.

[2] Chestnut RM. Secondary brain insults after head injury: clinical perspectives. New Horiz 1995; 3: 366-75.

[3] Chestnut RM, Marshall LF, Klauber MR, et al. The role of secondary brain injury in determining outcome from severe head injury. J Trauma 1993; 34: 216-22.

[4] Hartl R, Bardt TF, Biening KL, Sarrafzadeh AS, Schneider GH, Unterberg AW. Mannitol decreases ICP but does not improve brain-tissue $\mathrm{PbtO} 2$ in severely head-injured patients with intracranial hypertension. Ata Neurochir Suppl 1997; 70: 40-2.

[5] Gopinarh SP, Valadka AB, Uzura M, Robertson CS. Comparison of jugular venous oxygen saturation and brain tissue pO2 as monitors of cerebral ischemia after head injury. Crit Care Med 1999; 27: $2337-45$.
[6] Kiening KL, Unterberg AW, Bardt TF, Schneider GH, Lanksch WR. Monitoring of cerebral oxygenation in patients with severe head injuries: brain tissue $\mathrm{pO} 2$ versus jugular vein oxygen saturation. J Neurosurg 1996; 85: 751-7.

[7] Kiening KL, Schneider GH, Bardt TF, Unterberg AW, Lanksch WR. Bifrontal measurements of brain tissue-PbtO2 in comatose patients. Acta Neurochir Suppl 1998; 71: 172-3.

[8] Marion DW, Darby J, Yonas H. Acute regional cerebral blood flow changes caused by severe head injuries. J Neurosurg 1991; 74: 40714.

[9] Narayan RK, Kishore PR, Becker DP, et al. Intracranial pressure: to monitor or not to monitor? A review of our experience with severe head injury. J Neurosurg 1982; 56: 650-9.

[10] Robertson CS, Gopinath SP, Uzura M, Valadka AB, Goodman JC. Metabolic changes in the brain during transient ischemia measured with microdialysis. Neurol Res 1998; 20(Suppl): S91-4.

[11] Bouma GJ, Muizelaar JP, Stringer WA. Ultra-early evaluation of regional cerebral blood flow in severely head-injured patients using xenon-enhanced computerized tomography. J Neurosurg 1992; 77: 360-8.

[12] Robertson C. Desaturation episodes after severe head injury: Influence on outcome. Acta Neurochir Suppl (Wien) 1993; 59: 751-7.

[13] Palmer S, Bader MK, Qureshi A, et al. The impact on outcomes in a community hospital setting of using the AANS traumatic brain injury guidelines. Am Assoc Neurol Surg J Trauma 2001; 50: 65764.

[14] Graham DI, Ford I, Adama JH, et al. Ischaemic brain damage is still common in fatal non-missile head injury. J Neurol Neurosrg Psychiatry 1989; 52: 346-50.

[15] van Santbrink H, Maas A, Avezaat CJJ. Continuous monitoring of partial pressure of brain tissue oxygen in patients with severe head injury. Neurosurgery 1996; 38(1): 21-31.

[16] Artu F, Jourdan C, Perret-Liaudet A, Charolot M, Mottolese C. Low brain tissue oxygen pressure: incidence and corrective threrapies. Neurol Res 1998; 20(Suppl): S48-51.

[17] van den Brink WA, van Santbrink H, Steyerberg EW. Brain oxygen tension in severe head injury. Neurosurgery 2000; 46(4): 86876.

[18] Stocchetti N, Chieregato A, De Marchi M, Croci M, Benti R, Grimoldi N. High cerebral perfusion pressure improves low values of local brain tissue $\mathrm{O} 2$ tension (ptiO2) in focal lesions. Acta Neurochir 1998; 71(Suppl): 162-5.

[19] Schoon P, Benito Mori L, Orlandi G, Larralde C, Radrizzani M. Incidence of intracranial hypertension related to jugular bulb oxygen saturation disturbances in severe traumatic brain injury patients. Acta Neurochir Suppl 2002; 81:285-7.

[20] Cuza A, Figueredo Mendez J, Castellanos Gutierrez R, Gomez Peyre F. Monitorization of the jugular oxygen saturation jugular and cerebral ischaemia in the neurocritical patient (Spanish). Rev Neurol 2001; 33(6): 511-3.

[21] Bardt TF, Unterberg AW, Hartl R, Kiening KL, Schneider GH, Lanksch WR. Monitoring of brain tissue PO2 in traumatic brain injury: effect of cerebral hyposia on outcome. Acta Neurochir Suppl 1998; 71: 153-6.

[22] Dings J, Meixensberger J, Jager A, Roosen K. Brain tissue pO2 and outcome after severe head injury. Neurol Res 1998; 20(Suppl 1) S71-5.

[23] Stiefel MF, Spiotta A, Gracias VH, Garuffe AM, Guillamondegue O, Maloney-Wilensky E. Reduced mortality rate in patients with severe traumatic brain injury treated with brain tissue oxygen monitoring. J Neurosurg 2004; 101: 424-44.

[24] Latronico N, Beindorf AE, et al. Limits of intermittent jugular bulb oxygen saturation monitoring in the management of severe head trauma patients. Neurosurgery $2001 ; 48(2)$ : 454-6.

[25] Bader MK, Littlejohns LR, March K. Brain tissue oxygen monitoring in severe brain injury, II: Implications for critical care teams and case study. Crit Care Nurse 2003; 23(4): 29-38 and 40-2. 